\title{
Testing concurrent benefits for Section 12L tax incentives in South Africa
}

\author{
W. Hamer ${ }^{1 *}$, E.H Mathews ${ }^{2}$, A.G.S. Gous ${ }^{3}$, J. Booysen $^{4}$, J.C. Vosloo ${ }^{5}$ \\ Centre of Research and Continued Engineering Development, North-West University; consultants to Enermanage \\ (Pty) Ltd and ETA Operations (Pty) Ltd, PO Box 11207, Silver Lakes 0054, South Africa \\ 1 https://orcid.org/0000-0002-0481-3098 2 https://orcid.org/0000-0001-5425-6368 \\ 3 https://orcid.org/0000-0002-3195-1146 4 https://orcid.org/0000-0001-7137-2678 \\ 5 https://orcid.org/0000-0003-1063-0252
}

\begin{abstract}
The South African energy crisis harms the economy. Tax incentives are intended to help, but rules for incentives must be understood by all stakeholders for taxpayers to be encouraged to invest. Section $12 \mathrm{~L}$ (S12L) is relatively new legislation that allows a tax deduction for verified year-on-year energy efficiency savings in South Africa. Concurrent benefits are excluded from this tax incentive, to prevent a double reward for the same activity. Although the prevention of double benefits is commonly addressed in the field of measurement and verification (M\&V), non-technical guidelines are not available. This is a critical shortcoming since multiple professions (tax, audit and legal) need to understand the technical M\&V requirements of S12L. This study reviews the current legislation and interpretations of concurrent benefits in terms of S12L. It shows that multiple energy-related incentives are utilised by industries and that, therefore, it must be determined if different programmes overlap, so as to create concurrent benefits with S12L. It is then critical to correctly apply M\&V practice to ensure exclusion of concurrent benefits. This study also provides a simplified methodology to evaluate concurrency, based on the $S 12 \mathrm{~L}$ regulatory requirements and standard M\&V methods. Three case studies show how concurrency can occur and how M\&V practice is applied to exclude double benefits. The test for concurrency is shown to reduce to the following question: Is the same energy saving funded twice? The tests must be done to ensure no double benefit occurs.
\end{abstract}

Keywords: energy efficiency; measurement and verification; concurrency; multidisciplinary communication

\section{Highlights:}

- $\quad$ Multiple energy efficiency and power generation programmes are required to address the energy crisis South Africa.

- $\quad$ Concurrency tests are developed to ensure double rewards are not paid for the same energy efficiency savings.

- Simple and clear communication of the technical tests to different disciplines (e.g. energy, tax, audit and legal) is important.

- $\quad$ Proposals for policy development and communication of S12L incentives and carbon tax are made.

Journal of Energy in Southern Africa 31(4): 57-71

DOI: https://dx.doi.org/10.17159/2413-3051/2020/v31i4a8674

Published by the University of Cape Town ISSN: 2413-3051

This work is licensed under a Creative Commons Attribution-ShareAlike 4.0 International Licence

https://journals.assaf.org.za/jesa

Sponsored by the Department of Science and Innovation

Corresponding author: email: whamer@researchtoolbox.com 


\section{Introduction and relevance Background on the Section $12 \mathrm{~L}$ tax incen- tive}

National energy supply shortfalls have become a critical problem in South Africa [1]. Among multiple initiatives, the Section 12L (S12L) energy efficiency incentive of the Income Tax Act (no. 58 of 1962) [2], is intended to help continued energy supply and combat the adverse effects of greenhouse gas emissions [3]. According to the National Energy Efficiency Strategy, the incentive will lead to 42 PJ energy savings [4], which makes it the most significant energy efficiency (EE) incentive [5]. S12L incentivises new EE savings with an income tax deduction of ZAR 0.95 per kWh [6]. As the verification of EE savings is highly technical, measurement and verification $(\mathrm{M} \& \mathrm{~V})$ entities accredited by the South African National Accreditation System (SANAS) are appointed to quantify claims based on the SANS 50010 standard and submit reports to the South Africa National Energy Development Institute (SANEDI) [3], [7], [8]. SANEDI is legally appointed to further evaluate compliance of S12L applications before issuing an EE savings certificate to the taxpayer [3].

Multiple mechanisms are required to improve South African energy shortfalls, of which S12L is one [3]. However, several other state-funded programmes are also available, which raises the concern of concurrent benefits being claimed [9]. If there is uncertainty it will create reluctance to use energy-related investments to the detriment of the country. This topic is discussed in the next section.

\section{Concurrent benefits in industry}

The concept of excluding concurrent benefits was introduced to prevent savings that have already been incentivised being also claimed under S12L. For example, EE savings achieved through the Eskom Standard Offer Programme [10] cannot also be claimed under S12L [9]. Concurrency is thereby excluded, to prevent the fiscus from paying twice for the same EE savings. It follows that Section 12L paragraph 4 (S12L(4)) excludes a concurrent benefit in respect of EE savings [2]. The activities that can generate concurrent benefits are listed under Regulation 7 [3], as shown in Figure 1.

In addition to Regulation 7 [3], official interpretations of a concurrent benefit in terms of S12L have been documented by the South African Revenue Service (SARS) [7], [11], [12], as shown in Figure 2.

Different interpretations agree that a concurrent benefit is not allowed in respect of the same EE savings. The exclusion of concurrency, therefore, prevents so-called 'double-dipping' or 'double counting'. Internationally, this is a general requirement, as explained by the $M \& V$ guideline extract reproduced in Figure 3 [13]. The interpretation of concurrent benefits reduces to the key question: Is the same energy saving funded twice?

In South Africa, multiple incentive programmes are utilised in the energy sector [14], including those related to tax, investment, manufacturing, energy supply, or energy demand. Although these may have different purposes, it is possible that overlapping may occur when more than one programme is

The law (Section 12L (4) of the Income Tax Act 58 of 1962):

(4) A deduction must not be allowed in terms of this section if the person claiming the allowance receives any concurrent benefit in respect of energy efficiency savings.

The Regulations (in terms of Section 12L of the Income Tax Act 58 of 1962):

7. For the purposes of section $12 \mathrm{~L}(4)$ of the Income Tax Act any credit, allowance, grant, cost recovery agreement or other similar benefit granted by or through-

(a) any sphere of government;

(b) any public entity that is listed in Schedule 2 or 3 to the Public Finance Management Act, 1999 (Act No. 1 of 1999); or

(c) any power purchase agreement as defined in Electricity Regulations on New Generation Capacity made by the Minister of Energy under section 35(4) of the Electricity Regulation Act, 2006 (Act No. 4 of 2006) published by Government Notice 721 of 5 August 2009 in respect of the IPP bid programme as defined in those regulations,

for any energy efficiency savings or the sale and purchase of electricity constitutes a concurrent benefit.

Figure 1: Extract from S12L Act and Regulations [2], [3]. 
SARS Interpretation (draft, 2016) notes "a concurrent benefit relating to the energy-efficiency savings will not be able to claim a deduction under section $12 \mathrm{~L}$."

SARS Interpretation (Issue 1, 2017) notes that "a concurrent benefit relating to the same energy-efficiency savings will not be able to claim a deduction under section $12 \mathrm{~L}$." and that "Essentially, the exclusion of concurrent benefits prevents a double benefit for the same activity"

SARS Interpretation (Issue 2, 2019) reiterates that "a concurrent benefit relating to the same energy-efficiency savings will not be able to claim a deduction under section $12 \mathrm{~L}$."

Figure 2: Extract from South African Revenue Service Interpretation Note 95 [7], [11], [12] (emphasis added).

\author{
"Double counting occurs when the MWh savings from a single EE program, EE project, or \\ EE measure are counted more than once. It is critical to prevent this type of error to \\ maintain programmatic integrity and credibility, and to ensure that EE activities result in \\ real and permanent reductions in emissions."
}

\title{
Figure 3: Extract from Guidebook for Energy Efficiency Evaluation, Measurement, and Verification
} [13] (emphasis added).

utilised by the same entity. Table 1 summarises the uptake statistics of different programmes. The high uptake indicates a high probability of concurrency within taxpayers' organisations. However, stakeholders should take note that not all programmes have the same purpose. For example, not all lead to energy savings. A good example is power purchase agreements (PPAs) for electricity generation. There are multiple types of PPA, e.g. Independent power producer bid PPA for new generation capacity or the Short-Term Power Purchase Programme (STPPP).

IPP-bid PPA projects are usually renewable energy projects [23] which lead to a reduction in electricity bought. This reduction can be viewed as an EE saving and IPP-bid PPA is therefore well-described in Regulation 7 as a concurrent benefit (Figure 1). On the other hand, STPPP [17] is an emergency PPA to reduce electricity load shedding using existing power generation facilities, which typically convert non-renewable fuel into electricity [24]. Typically, it takes three units of fossil fuel to generate one unit of STPPP electricity, using a conversion efficiency of 33\% (typical coal or gas power plants can range between $32 \%$ and $42 \%$ [25]). This is not an EE saving, as it leads to higher total energy consumption due to increased conversion efficiency losses. STPPP is thus not mentioned in Regulation 7 on concurrency as it is physically impossible for it to be concurrent with a 12L EE saving. However, fundamental M\&V principles must still be followed to determine this.

Since multiple programmes are active in the South African energy sector, assurance is required that no double benefits are claimed for the same activities. However, the existing $M \& V$ procedures that can be applied to prevent double benefits are considered highly technical [7]. This is especially problematic in the case of S12L as a tax-based mechanism. Inevitably, multiple finance-related disciplines - from tax, audit and legal, fields, in addition to $\mathrm{M} \& \mathrm{~V}$ professionals - are involved with the process. Clear and logical communication is critical.

\section{Problem statement}

Multiple programmes are incentivised for different purposes (Table 1). If it is automatically assumed that all activities are concurrent benefits, it will have a detrimental impact on energy-related programmes in South Africa - for example, where a PPA intended to reduce Eskom load shedding can be invalidated by a separate completely different $\mathrm{EE}$ project, and vice versa. If taxpayers are unsure if concurrent benefits are applicable for different programmes, then S12L will not be an effective driver for EE investments. 
Table 1: Summary of incentive programmes related to energy in South Africa.

\begin{tabular}{|c|c|c|}
\hline Incentive programmes & Description & $\begin{array}{c}\text { Occurrence or uptake in } \\
\text { practice }\end{array}$ \\
\hline \multirow[t]{2}{*}{$\begin{array}{l}\text { Integrated demand manage- } \\
\text { ment (IDM) }\end{array}$} & $\begin{array}{l}\text { Projects in industrial and mining process } \\
\text { optimisation and efficiency upgrades }\end{array}$ & 199 projects [15] \\
\hline & $\begin{array}{l}\text { Mass roll-out projects (mostly compact } \\
\text { fluorescent lightbulbs) }\end{array}$ & 318 projects [15] \\
\hline $\begin{array}{l}\text { Independent power producer } \\
\text { (IPP) bid programme power } \\
\text { purchase agreement (PPA) }\end{array}$ & $\begin{array}{l}\text { Electrical energy purchased under an IPP- } \\
\text { bid programme }\end{array}$ & $755 \mathrm{MW}[16]$ \\
\hline $\begin{array}{l}\text { Demand market participation } \\
\text { (DMP) }\end{array}$ & $\begin{array}{l}\text { Demand-side load management from } \\
\text { various participants }\end{array}$ & $1356 \mathrm{MW}[16]$ \\
\hline $\begin{array}{l}\text { Short-Term Power Purchase } \\
\text { Programme (STPPP) }\end{array}$ & $\begin{array}{l}\text { During 2015, Government War Room } \\
\text { extended STPPP to sustain electricity } \\
\text { supply during Eskom supply constraints }\end{array}$ & $862 \mathrm{MW}[17]$ \\
\hline $\begin{array}{l}\text { Renewable Energy Independent } \\
\text { Power Producer Programme } \\
\text { (REIPPP) }\end{array}$ & $\begin{array}{l}\text { Department of Energy approves } \\
\text { renewable energy generation under IPP- } \\
\text { bid programmes }\end{array}$ & 3887 MW [16] \\
\hline Section $12 \mathrm{~K}$ tax incentive & $\begin{array}{l}\text { Income tax exemption on the trading of } \\
\text { certified emission reduction (CER) units }\end{array}$ & $\begin{array}{l}12 \text { CER projects [18] } \\
\text { Cancelled in } 2019 \text { [19] }\end{array}$ \\
\hline Section 12I tax incentive & $\begin{array}{l}\text { Tax incentive for greenfield and } \\
\text { brownfield industrial policy projects }\end{array}$ & $\begin{array}{l}58 \text { projects approved } \\
{[20],[21]}\end{array}$ \\
\hline Section $12 \mathrm{~L}$ tax incentive & $\begin{array}{l}\text { Tax incentive for verified energy } \\
\text { efficiency savings }\end{array}$ & $\begin{array}{c}108 \text { projects registered } \\
{[22]}\end{array}$ \\
\hline
\end{tabular}

SANAS-accredited M\&V professionals and SANEDI panellists are legally appointed to conduct a technical evaluation which includes evaluation of concurrency. However, $\mathrm{M} \& \mathrm{~V}$ is a highly technical field [7] and it is necessary to communicate to all stakeholders how possible double benefits are excluded from S12L claims. This requires the development of a method to test for possible concurrent benefits based on the existing S12L regulatory structure. The method should be easily understandable to convey the results to disciplines outside of the $M \& V$ profession, but at present there are no simplified technical guidelines to convey the necessary M\&V concepts in the context of the S12L tax incentive. This study provides easy-to-follow simplified guidelines to understanding the evaluation of possible concurrency of S12L EE savings. The method of the study is described in the next section.

\section{Methodology}

\subsection{Overview of methodology}

When evaluating a concurrent benefit in terms of S12L, some basic M\&V concepts must be considered, and are explained in this section. The conceptual overview of the study is shown in Figure 4. Firstly, four basic M\&V concepts are discussed (Section 2.2). The concepts are derived directly from the S12L regulations [3] and SANS 50010 [8]. These concepts are then used to develop specific logical tests for concurrency (Section 2.3). The tests are then applied to case studies (Section 3). Finally, the case study results are discussed to recommend a set of proposals for policy development and communication (Section 4).

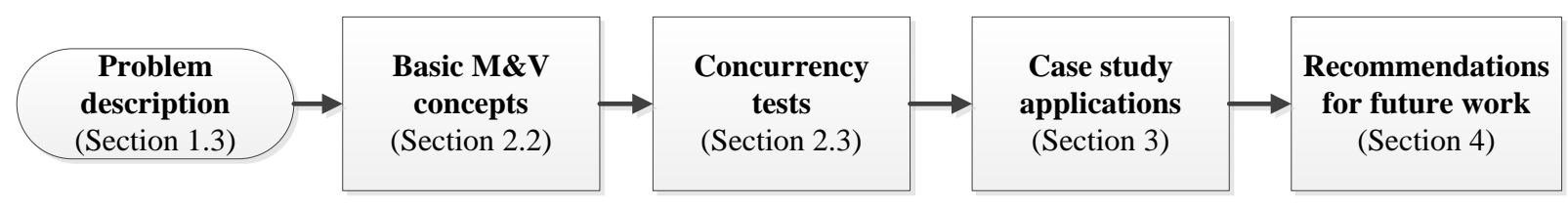

Figure 4: Overview of the study. 


\subsection{Basic M\&V concepts}

2.2.1 Concept 1: Definition of energy efficiency savings

The concept of 'Energy efficiency savings' is defined in the S12L Regulations [3] and SANS 50010 [8], as shown in Figure 5. According to the definition, energy efficiency savings are only relevant to S12L when compared to the same activity, time period and conditions. The same should be considered when evaluating possible concurrency of overlapping or different activities. If there is no EE saving, then there can be no S12L application. Consequently, if a concurrent activity is not in respect of an EE saving there can also be no concurrent benefit with S12L.

\subsubsection{Concept 2: Measurement boundary selection}

The word 'boundary' is found 28 times in the latest SANS 50010 standard [8]. This is because the standard allows different measurement boundaries to quantify the effects from the energy-saving measures [8] as shown in Figure 6, indicating that two basic boundary options are available, namely (1) evaluating the whole facility with multiple projects, and (2) isolating a portion of a facility to claim individual projects. The green boundary only eval-

Concept 1: Energy efficiency savings means "the difference between the actual amount of energy used in the carrying out of an activity or trade, in a specific period and the amount of energy that would have been used in the carrying out of the same activity or trade during the same period under the same conditions if the energy-efficiency savings measure was not implemented".

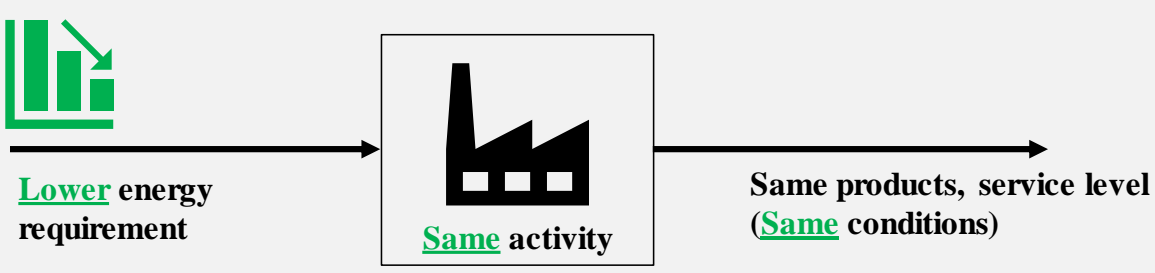

Figure 5: M\&V concept 1 - Definition of energy efficiency savings [3], [8].

Concept 2: Measurement boundary means that "Savings shall be determined for either an entire facility or for a portion of it."

Whole facility option: "The energy performance of the whole facility will be assessed, not just the energy savings measures"

Isolated boundary: "A measurement boundary shall be drawn around the activity in question"

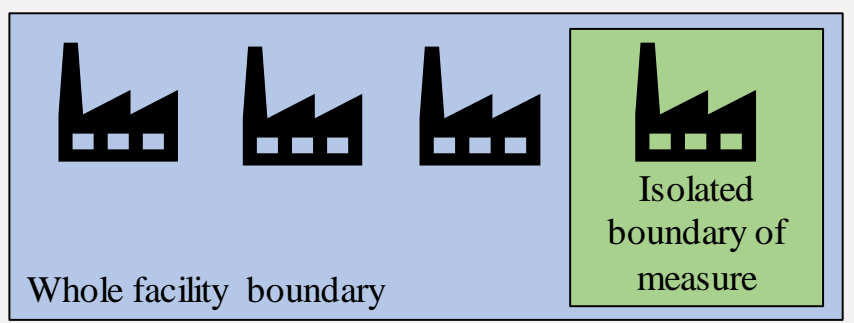

Figure 6: $M \& V$ concept 2 - Measurement boundary [8]. 
uates the sections where the intervention is implemented. This isolates the effects of the energy-saving measure specifically. The treatment of concurrent benefits also relies on boundary selection: a boundary can either include or exclude the effects of concurrent activities, while accounting for possible interactive effects or energy switches. The implications of both boundary options must be considered by the $M \& V$ entity.

\subsubsection{Concept 3: Baseline and assessment periods}

The S12L Regulations require a baseline period based on the preceding year of assessment [3]. Only new EE savings achieved in an assessment year relative to the preceding year can then be measured for the purpose of claiming S12L EE savings. This is described in Regulation 5 [3] and the relevant SARS interpretation [7], as shown in Figure 7. Note that each bar in Figure 7 is adjusted to the same conditions (e.g. same product or service level) as the assessment year. This is done with routine adjustments as described in SANS 50010 [8]. The baseline requirement is a built-in protective mechanism that ensures that S12L only incentivises new energy efficiency activities. This automatically excludes preexisting savings from the S12L energy calculations (shown by the red change in Figure 7). It follows that only a year-on-year change is claimable under S12L (shown by the change marked with "B"). The pre-existing changes are fundamentally excluded (shown by the change marked with "A"). The S12L baseline requirement should be considered when evaluating concurrency and is one of the important elements to avoid possible concurrent benefits.

\subsubsection{Concept 4: Conservative reporting}

The SANS 50010 standard was developed to deliver conservative results [8]. This means that the $\mathrm{M} \& \mathrm{~V}$ methodology must account for possible uncertainties that may affect the reported savings. Conservativeness is required to the extent that reported savings cannot be invalidated by a more rigorous calc-

Concept 3: Baseline and assessment periods are defined in Regulation 5 which states that baseline calculation must take into account the "immediately preceding year of assessment for which the allowance was claimed".

Based on Regulation 5, the SARS Interpretation Note 95 states the following:

- "the baseline will have to be reset for every year of assessment"

- "energy efficiency savings generated in a particular year of assessment cannot be carried forward and used to calculate the deduction in a following year"

- "moreover, the baseline should be adjusted in accordance with the standard and included in reporting in a way that ensures there is no duplication of savings"

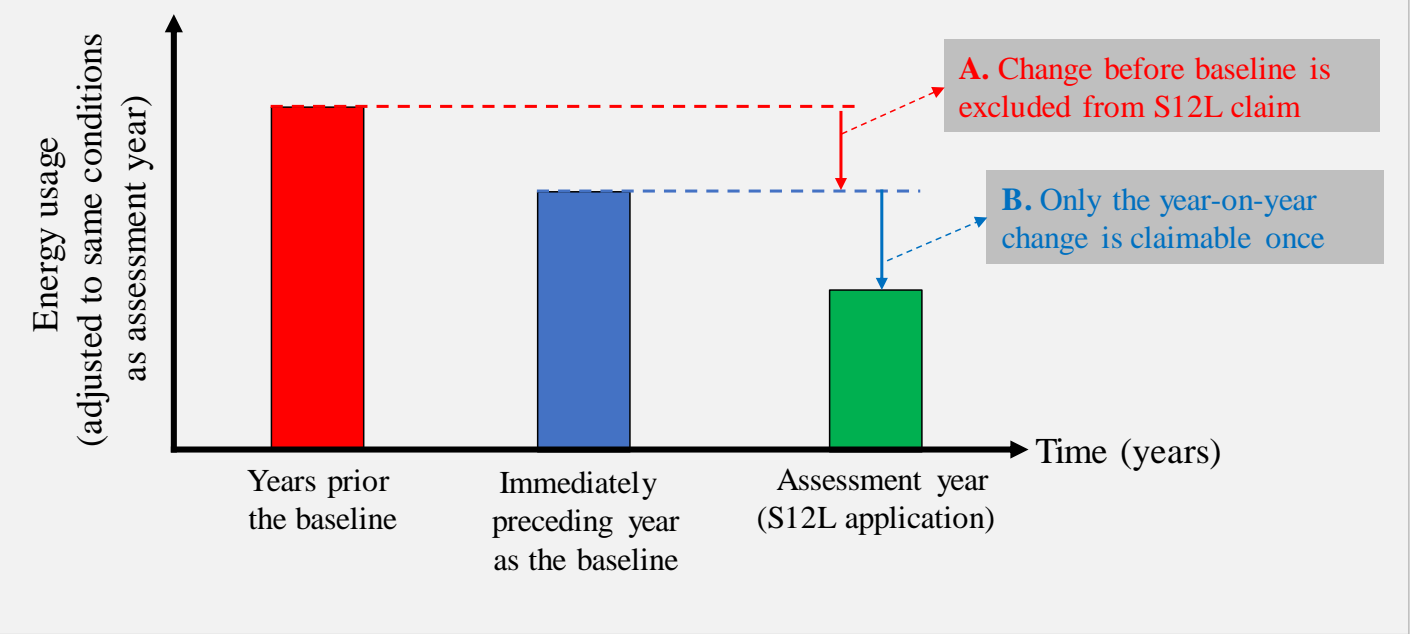

Figure 7: M\&V concept 3 - Baseline and assessment periods [3], [7]. 
Concept 4: Conservative reporting means that "Uncertainty shall be managed to ensure that reported savings are likely to be conservative" and the "management of uncertainty shall include, but are not limited to the following:"

- "calculation method chosen"

- "M\&V boundaries chosen"

- "possible consequential effects not included in the M\&V result"

- "an estimation of interactive effects"

"Uncertainty shall be taken into account such that more accurate measurement or a more rigorous M\&V process cannot invalidate the result."

"In this context, invalidating a result means that "lower savings" is reported."

Figure 8: M\&V concept 4 - Conservative reporting [8].

culation. The standard makes specific statements relating to conservative reporting [8], as shown in Figure 8. It acknowledges that M\&V uncertainties exist in practice. Conservative reporting therefore lowers the risk of overreporting [26]. Conservative calculations and non-routine adjustments must be applied to ensure that concurrent benefits are excluded from S12L claims. In these cases, the reported savings will be biased towards a lower result to avoid effects that cause an overstated result or double benefit.

\subsection{Development of concurrency tests}

\subsubsection{0verview of concurrency tests}

The M\&V concepts discussed in the preceding section are used to formulate concurrency tests in this section. Although M\&V is a highly technical process [7], the tests can be simplified into logical requirements, as summarised in the decision tree shown in Figure 9. Each requirement in Figure 9 is discussed below. The tests are initiated by identifying the incentive programmes within a taxpayer's organisation which may overlap with a S12L claim (possible overlapping programmes are listed in Table 1). The tests are then applied to case studies in the next section.

\subsubsection{Requirement 1: Same activity?}

The first test asks whether a concurrent activity and the S12L activity are distinguishable based on the definition of energy savings (i.e. Concept 1 discussed in Section 2.2.1). The distinguishing factors can relate to different time periods, impacts, purposes, locations, actions, or other relevant aspects. If there are no distinguishable factors, then a concurrent benefit may very likely exist which cannot be claimed under S12L. Alternatively, if the activities can be distinguished from each other, then it cannot be assumed to be a concurrent benefit at face value. Further investigation is then required (refer to Requirement 2).

\subsubsection{Requirement 2: Same boundary for baseline and assessment?}

$\mathrm{M} \& \mathrm{~V}$ professionals must inter alia select an appropriate measurement boundary based on several factors prescribed by SANS 50010 [8], [27], [28]. The appropriate selection of this boundary is critical to ensure that representative results are quantified, by accounting for all parameters of the boundary (based on Concept 2 discussed in Section 2.2.2). This is especially important when considering interactive effects or energy switches - for example, reducing electricity by running a generator inside a boundary. If the generator's fuel parameter is not monitored, it will look like an efficiency improvement when in fact more fuel will be required for the same electricity usage (i.e. no energy efficiency). The test therefore requires an assertion that boundary accounts for all energy sources consistently for both the baseline and assessment evaluation. If boundary selection is done consistently, then further investigation can be continued (refer to Requirement 3).

\subsubsection{Requirement 3: Concurrent activity inside the same evaluation boundary?}

As stated in Requirement 2, an appropriate measurement boundary must be selected [8], [27]. If the S12L evaluation boundary excludes the EE savings from a concurrent activity, then a concurrent benefit is excluded from a S12L claim. This can be the case 


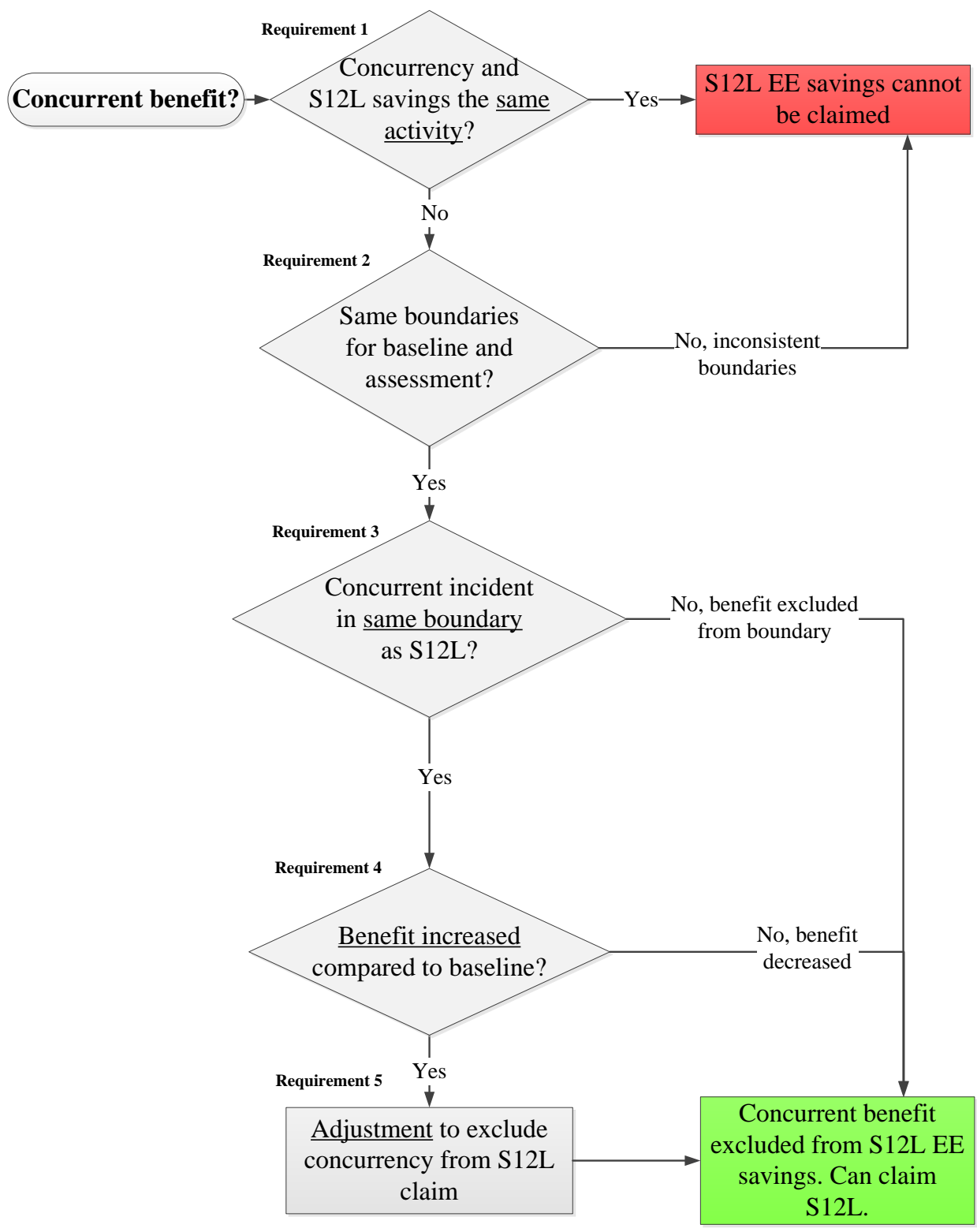

Figure 9: Decision tree summarising concurrency tests.

when an isolated boundary is selected to only encapsulate a S12L activity's impact. If a whole facility boundary is more appropriate (as when multiple EE projects are implemented at the same facility), then it is likely that a concurrent activity will also be included in the same boundary (refer to Table 1 for a list of possible concurrent activities). All energy effects are included in a whole facility boundary. This type of boundary may include the effects of concurrent activities which can possibly lead to an overlapping benefit being claimed under S12L as well. If the boundary includes the energy streams (e.g. whole facility boundary) or if unaccounted interactive effects are caused by the concurrent activity, then a concurrent benefit is possible. This must be investigated further (refer to Requirement 4).

\subsubsection{Requirement 4: Benefit of concurrent activity} increased compared to baseline?

A S12L application requires a year-on-year comparison and only the year-on-year benefit is claimable. Under the same rule, a concurrent activity must show a year-on-year increase to create a claimable concurrent benefit (based on Concept 3 discussed in Section 2.2.3). If a concurrent benefit's impact decreases (essentially showing a negative saving or a cancellation of the benefit) then there is no measurable improvement, and nothing can be claimed under S12L. It is therefore impossible to claim a concurrent benefit if there is no year-on-year increase in that benefit. If a benefit decreases or stays the same, then it will not cause a concurrent benefit. However, the effects of such a decrease must still be 
investigated, to understand if it impacts the S12L application in any other way (other than concurrency). It follows that only the year-on-year increase in a concurrent activity's benefit can possibly overlap with S12L. If an increase is measured, then further investigation is required to determine the extent of overlapping which must be removed from the S12L application to avoid claiming a double benefit (refer to Requirement 5).

\subsubsection{Requirement 5: Adjustment required to exclude from S12L claim?}

Requirement 5 is applicable if it has been established that a concurrent activity's benefits increased (Requirement 4), while applicable to the same measurement boundary (Requirement 3) as a S12L application. The question that needs to be answered is whether the concurrent activity's increase is also being claimed as a S12L EE saving. If overlapping is identified, then the concurrent quantities need to be removed (i.e. an adjustment) from the energy savings intended for the S12L application. A technical evaluation is required to determine the appropriate adjustment to isolate and exclude possible concurrent benefits from S12L claims [29]. If applicable, a non-routine adjustment must be made to exclude a possible double benefit, which is an unintended consequential effect, from the $M \& V$ result. A non-routine adjustment refers to unusual changes in relevant variables or factors [8] (which in this case refers to a change in a concurrent benefit which is not intended for the S12L application). If uncertainty exists surrounding the exact adjustment, the principle of conservative reporting must be applied to ensure full exclusion of possible concurrent benefits (i.e. likely overestimate the impact from concurrency). This requirement is based on Concept 4 discussed in Section 2.2.4.

\subsection{Concurrency tests conclusion}

Five concurrency tests are developed in this study. Each test is based on a requirement which is traceable to the basic M\&V concepts from the S12L regulations [3] and SANS 50010 [8]. In the next section, the concurrency tests are applied to three case studies. Each case study has a different scenario to illustrate the practical application of the tests.

\section{Results and discussion}

\subsection{Overview of case studies}

This study presents three case studies. Case study A is based on an existing S12L application where concurrency was tested to evaluate how it is done by a SANAS-accredited M\&V body and SANEDI review panel. Case studies B and $C$ are based on hypothetical scenarios to demonstrate the extent of the developed concurrency tests. Note that the full details of each case study are not discussed (i.e. system details, M\&V plan, baseline model, routine adjustments, etc.), with only the necessary information related to concurrency presented. The hypothetical case studies (B and C) are based on simplified scenarios, to illustrate the extent of the concurrency tests.

\subsection{Case study A: Eskom-funded project within evaluation boundary}

\subsubsection{Background}

Case study A is set on a South African mining operation. As for most underground mines, energy-intensive systems are required, including refrigeration, dewatering, compressed air and ventilation. In this example, the energy-saving focus was placed on compressed air network optimisation. The optimisation project led to measurable EE savings which were also claimed as a S12L tax allowance. As part of the S12L process, it was also disclosed that energy-saving initiatives at this mine were in the past partially funded by Eskom's Energy Efficiency and Demand Side Management (EEDSM) programme. The next section summarises the information that was gained by reviewing the formal $M \& V$ reports.

\subsubsection{Summary of the existing M\&V reports relating to concurrency}

The possible concurrency between EEDSM and S12L was disclosed in the M\&V reports which were compiled by a SANAS-accredited M\&V team and reviewed by a SANEDI-appointed panel. Based on the reports, it is derived that the EEDSM project was completed approximately four years before the S12L application. This time period information is summarised in Table 2.

Table 2: Case study A - Summary of activity difference.

\begin{tabular}{ccc}
\hline Indicator & EEDSM activity & S12L activity \\
\hline Baseline & June-August & Financial year \\
period & 2011 (FY12) & 2015 (FY15) \\
Assessment & April-June 2012 & Financial year \\
period & (FY12) & 2016 (FY16) \\
\hline
\end{tabular}

Although the S12L activity's baseline was measured after the EEDSM activity (thereby excluding its effects), the $M \& V$ reports also showed a multi-year analysis to determine whether a concurrent benefit was being claimed (i.e. claiming the same kWh saving twice). This is illustrated in Figure 10, which shows that the S12L baseline (FY15) is lower than the EEDSM target and the measured performance of the EEDSM project. It demonstrates that the mining operation, over multiple years, continuously improved the energy usage of the compressed air net- 
work (after and without additional EEDSM funding). This improvement was also not claimed under S12L. The S12L application is only for the incremental improvement from FY15 to FY16. This improvement is therefore distinguishable from the EEDSM project's improvement.

\subsubsection{Apply concurrency tests}

The concurrency tests are applied based on the information derived from the $\mathrm{M} \& \mathrm{~V}$ reports. The dis- cussion and the results of each test are summarised in Table 3, which shows evidence from the M\&V reports that no concurrent benefits were being claimed.

Although all the required information is disclosed in the M\&V reports, it still needs to be communicated in a simple and structured manner for all role-players to be satisfied. The concurrency tests are therefore useful to dissect a highly technical process into smaller logical facts.

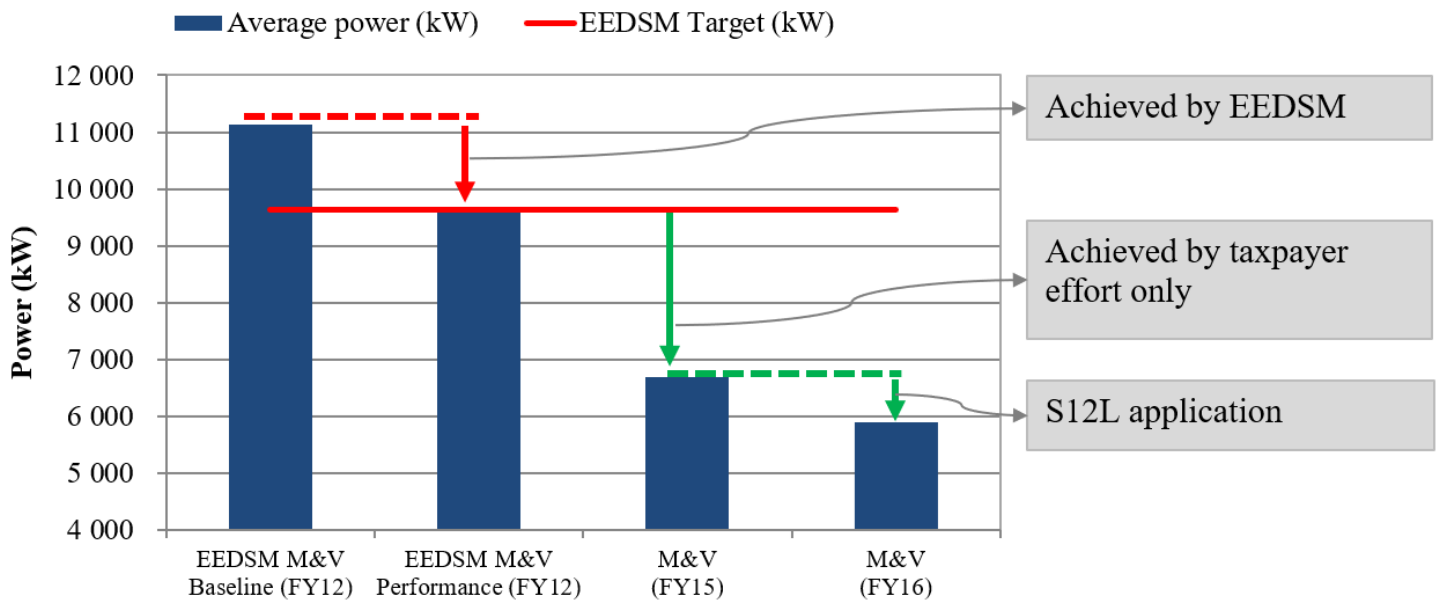

Figure 10: Multi-year energy comparison to show the difference between EEDSM and S12L application.

Table 3: Summary of concurrency tests (Case study A).

\begin{tabular}{|c|c|c|c|}
\hline No. & Concurrency test & Discussion & Result \\
\hline 1 & Same activity? & $\begin{array}{l}\text { The activities are distinguished based on different implementation } \\
\text { periods. The S12L application focused on additional EE savings } \\
\text { over and above the EEDSM activities from four years earlier. } \\
\text { Hence, the EEDSM and S12L activities are different. }\end{array}$ & No \\
\hline 2 & $\begin{array}{l}\text { Consistent } \\
\text { boundary? }\end{array}$ & $\begin{array}{l}\text { The M\&V boundary was selected over the isolated compressor } \\
\text { system. The M\&V team applied the boundary consistently and } \\
\text { confirmed that no energy switches took place (i.e. only electricity is } \\
\text { supplied to the boundary in both baseline and assessment } \\
\text { periods). }\end{array}$ & Yes \\
\hline 3 & $\begin{array}{l}\text { Concurrent } \\
\text { activity inside } \\
\text { boundary? }\end{array}$ & $\begin{array}{l}\text { The EEDSM project was implemented on the same system as the } \\
\text { S12L application boundary. It was therefore necessary to conduct } \\
\text { additional investigation to determine if a concurrent benefit was } \\
\text { being claimed. }\end{array}$ & Yes \\
\hline 4 & $\begin{array}{l}\text { Change in } \\
\text { concurrent } \\
\text { activity benefit? }\end{array}$ & $\begin{array}{l}\text { The EEDSM was completed four years before the S12L application. } \\
\text { A multi-year comparison of the EEDSM project showed that the } \\
\text { S12L application was due to additional effort over and above } \\
\text { EEDSM target. Hence, there was no change to the EEDSM benefit } \\
\text { which makes claiming a concurrent benefit impossible. }\end{array}$ & $\begin{array}{l}\text { No } \\
\text { change }\end{array}$ \\
\hline 5 & $\begin{array}{l}\text { Adjustment } \\
\text { required? }\end{array}$ & $\begin{array}{l}\text { No adjustment was required since it was shown that no double } \\
\text { savings were claimable. }\end{array}$ & No \\
\hline
\end{tabular}

Final evaluation: The tests show sufficient proof that no concurrent benefit was claimed in the S12L application. 
Although the case study is based on formal SANAS-accredited M\&V reports and SANEDI reviews, for this case study stakeholders required additional assurance that no concurrent benefits were claimed (similar to the problem statement described in Section 1.3). This indicates a need for additional assurance which increases the administrative burden of utilising the S12L incentive.

\subsubsection{Case study A implications}

If an alternative finding had been reached, it would have meant that the older EEDSM was considered a concurrent benefit. This means that no additional EE effort would have been incentivised. This is to the detriment of EE efforts as intended by S12L and to the disadvantage to the South African industry that needs greater EE in order to improve resilience against climate change. Clear communication of the concurrency tests is therefore important to incentivise new EE savings and promote sustainable development.

During this study, the authors also reviewed 14 other S12L applications' M\&V reports which disclosed possible concurrent benefits. In each case, it was found that the relevant SANAS-accredited M\&V entity and SANEDI review panel correctly evaluated concurrent benefits based on the developed con- currency tests (as shown in Case study A). These results are not presented in this article, for brevity. The remainder of the case studies are based on hypothetical scenarios to demonstrate the extent of the developed concurrency tests.

\subsection{Case study B: Eskom integrated de- mand management-funded project inside evaluation boundary}

\subsubsection{Case study B background}

Case study B considers the scenario where a facility improved with a year-on-year EE saving as shown in Figure 11. In this scenario, the measurement boundary is drawn around the whole facility. An isolated EE project funded by Eskom IDM [15] is noted. The tests will be used to evaluate if a concurrent benefit exists if S12L is claimed for the whole facility.

\subsubsection{Apply concurrency tests}

The concurrency tests applied to this case study scenario are summarised in Table 4, which shows that the IDM project is likely the reason for the EE saving at the facility boundary since no other activity is noted. Based on this information a concurrent benefit will be claimed if a S12L is based on the whole boundary.

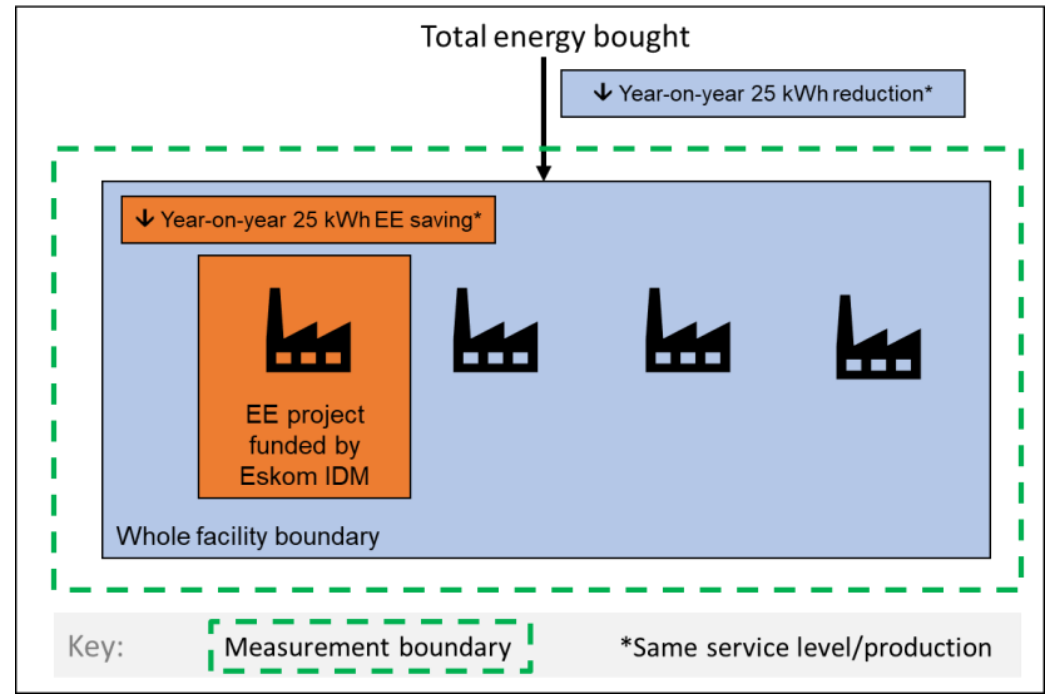

Figure 11: Case study B scenario and measurement boundary

Table 4: Summary of concurrency tests (Case study B)

\begin{tabular}{|c|c|c|c|}
\hline No. & Concurrency test & Discussion & Result \\
\hline 1 & Same activity? & $\begin{array}{l}\text { No other EE project or activity is disclosed. Hence it can } \\
\text { be stated that the concurrent activity's EE saving of } 25 \\
\text { kWh is the same as the activity being claimed in terms of } \\
\text { S12L at face value. }\end{array}$ & Yes \\
\hline 2 & $\begin{array}{l}\text { Consistent } \\
\text { boundary? }\end{array}$ & $\begin{array}{l}\text { The IDM project is based on an isolated boundary and the } \\
\text { S12L claim at the facility boundary. }\end{array}$ & Yes \\
\hline
\end{tabular}




\begin{tabular}{cllc}
\hline No. & Concurrency test & \multicolumn{1}{c}{ Discussion } & Result \\
\hline 3 & $\begin{array}{l}\text { Concurrent activity } \\
\text { inside boundary? }\end{array}$ & $\begin{array}{l}\text { The IDM project is in the same boundary as the S12L } \\
\text { claim. }\end{array}$ & Yes \\
4 & $\begin{array}{l}\text { Change in } \\
\text { concurrent activity } \\
\text { benefit? }\end{array}$ & $\begin{array}{l}\text { The IDM project showed year-on-year EE savings. Hence } \\
\text { it is a possible concurrent benefit. }\end{array}$ & Increased \\
& $\begin{array}{l}\text { Adjustment } \\
\text { required? }\end{array}$ & $\begin{array}{l}\text { An adjustment is required since the IDM project's benefit } \\
\text { increased in the same boundary. The adjustment should } \\
\text { be equal to the IDM project's EE saving to exclude a } \\
\text { possible concurrent benefit. In this hypothetical scenario } \\
\text { (see Figure 11), it means that zero savings can be claimed } \\
\text { for S12L (25 kWh - 25 kWh = 0 kWh). }\end{array}$ & Yes \\
\multicolumn{2}{c}{$\begin{array}{l}\text { Final evaluation: The first test shows sufficient proof that a concurrent benefit will be claimed if a } \\
\text { S12L application is based on the selected measurement boundary. The remainder of the tests supported } \\
\text { this finding. }\end{array}$} \\
\hline
\end{tabular}

\subsubsection{Implications}

In this case study, the measurement boundaries between the IDM and S12L are different, which might be seen to imply different activities. However, both boundary options would have resulted in the same year-on-year EE saving being claimed, resulting in a concurrent benefit. If such an occurrence is allowed it would mean that the sate fiscus would pay twice for the same EE savings. S12L would then not be an effective driver for new EE savings envisioned by the incentive.

\subsection{Case study C: Independent power pro- ducer-bid power purchase agreement in- side evaluation boundary}

\subsubsection{Case study C background}

Case study $C$ reflects a scenario where an IPP-bid PPA [23] is situated at a facility where a 12L claim is EE activity is also implemented. This is depicted in Figure 12. The tests will be used to evaluate if a concurrent benefit exists if S12L is claimed for the whole facility.

\subsubsection{Apply concurrency tests}

The concurrency tests applied to this case study scenario are summarised in Table 5. They show that an adjustment is required if a S12L application is based on the whole facility boundary, which includes the IPP-bid PPA. An alternative would be to isolate the S12L activity to exclude the IPP-bid PPA from the application.

\subsubsection{Case study C implications}

The concurrency tests show that a S12L application is possible, even if a concurrent benefit exists in the same boundary, given that the IPP-bid PPA and the S12L are fundamentally different activities in this case study. However, an adjustment is required to ensure that no double benefit is claimed for the selected whole facility boundary. Alternatively, an

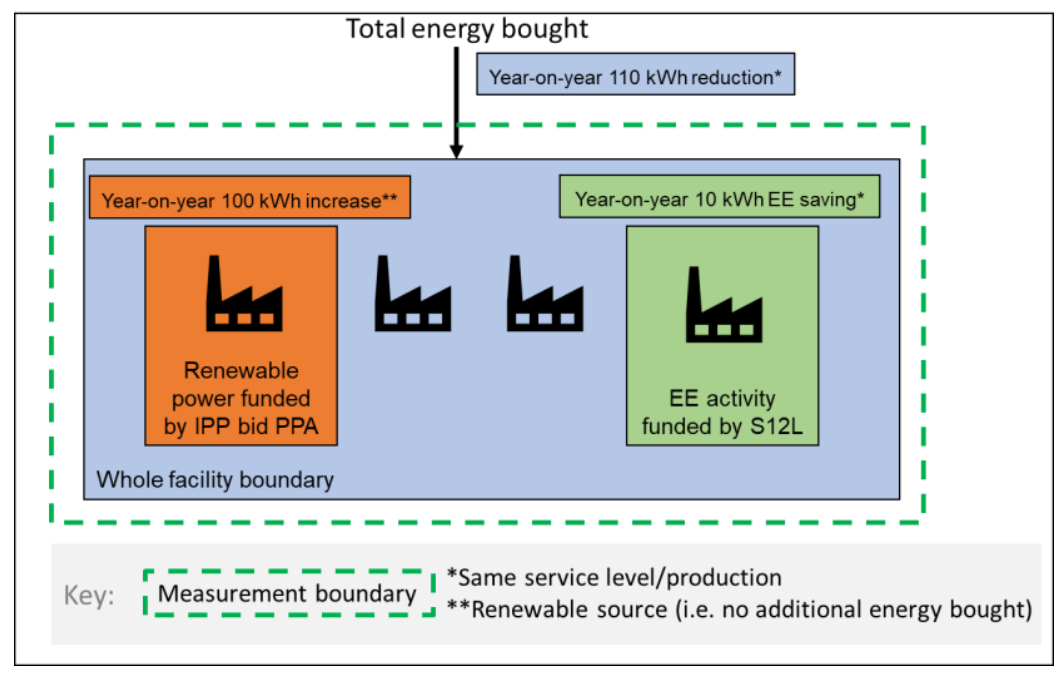

Figure 12: Case study $C$ scenario and measurement boundary 
Table 5: Summary of concurrency tests (Case study C)

\begin{tabular}{|c|c|c|c|}
\hline No. & Concurrency test & Discussion & Result \\
\hline 1 & Same activity? & $\begin{array}{l}\text { Different activities are disclosed. The IPP-bid activity } \\
\text { generated an additional } 100 \mathrm{kWh} \text {. The S12L activity in } \\
\text { isolation increased EE savings by } 10 \mathrm{kWh} \text {. In total, the facility } \\
\text { would then reduce external energy demand by } 110 \mathrm{kWh} \text {. }\end{array}$ & No \\
\hline 2 & $\begin{array}{l}\text { Consistent } \\
\text { boundary? }\end{array}$ & $\begin{array}{l}\text { Whole facility boundary is used consistently, and all energy } \\
\text { streams are accounted for. Note that external energy will } \\
\text { decrease owing to the use of renewable power plant for the } \\
\text { IPP-bid PPA. }\end{array}$ & Yes \\
\hline 3 & $\begin{array}{l}\text { Concurrent } \\
\text { activity inside } \\
\text { boundary? }\end{array}$ & $\begin{array}{l}\text { The IPP-bid PPA is inside the selected whole facility } \\
\text { boundary. }\end{array}$ & Yes \\
\hline 4 & $\begin{array}{l}\text { Change in } \\
\text { concurrent } \\
\text { activity benefit? }\end{array}$ & $\begin{array}{l}\text { The IPP-bid PPA generation increased, which lowered the } \\
\text { demand for energy as it replaced by a renewable source (e.g. } \\
\text { solar power). }\end{array}$ & Increased \\
\hline 5 & $\begin{array}{l}\text { Adjustment } \\
\text { required? }\end{array}$ & $\begin{array}{l}\text { An adjustment equal to the increase in electricity generation } \\
\text { would be required to exclude the possible concurrency from } \\
\text { the S12L application. Only the } 10 \mathrm{kWh} \text { by the separate S12L } \\
\text { activity is eligible ( } 110 \mathrm{kWh} \text { facility reduction - } 100 \mathrm{kWh} \\
\text { increase in electricity generation). }\end{array}$ & Yes \\
\hline \multicolumn{4}{|c|}{$\begin{array}{l}\text { Final evaluation: The tests show that a concurrent benefit can be claimed if no adjustment is } \\
\text { made in the fifth test. }\end{array}$} \\
\hline
\end{tabular}

isolated boundary could also have been used to exclude the IPP-bid PPA from the S12L activity. If an alternative conclusion was made, by stating that the presence of the IPP-bid PPA excluded all the other EE projects, then no separate EE effort would have been incentivised by S12L. This would be to the detriment of the facility's energy intensity. Conversely, if $\mathrm{EE}$ is claimed under $\mathrm{S} 12 \mathrm{~L}$, then the taxpayer would not have separately supplemented electricity supply, to the further detriment of the country's electricity shortfall.

The communication of the concurrency tests is therefore important to incentivise new EE savings while maintaining the ability to separately supply electricity to supplement national supply shortfalls. However, in the case of renewables, an overall decrease in external energy demand can create a concurrent benefit if not tested. In all cases, M\&V prudence is required to ensure that changes in energy usage are correctly quantified. This will be more complex in real-world applications. The concurrency tests will therefore be useful with structured guidance as cases become more complex. If it was automatically assumed that both activities are concurrent then no separate EE effort would have been incentivised by S12L. The tests are therefore suitable to convey the steps taken to exclude possible concurrent benefits.

\subsection{Summary of results}

If it is automatically assumed that activities, e.g. a PPA or all EE projects, are concurrent benefits in terms of S12L, it would have a detrimental impact on energy-related programmes in South Africa. From the case studies it is clear that concurrency tests are necessary. If concurrency tests are not applied, taxpayers will only be able to use one incentive for one specific activity, and not multiple incentives for different activities. This would lead to unbusinesslike results, as different incentive programmes have different purposes. Hence, this study validates a case for taxpayers to assist the country energy situation with both EE and private power generation if done separately.

The case studies indicate that taxpayers need to account for possible questions from various roleplayers when claiming S12L. This is in addition to the regulatory requirements of appointing a SANASaccredited M\&V body and SANEDI review panel. This adds to the administrative burden of claiming the allowance. However, the use of concurrency tests can aid taxpayers to evaluate whether possible concurrency risks apply to their S12L claims. It can also help other role-players to determine if possible double benefits were unduly claimed under S12L. By improving communication, it will also improve the efficiency of the S12L process. 
Note that the developed concurrency tests cannot replace prudence applied by legally appointed M\&V bodies and SANEDI review panels. It can only supplement the legally required $M \& V$ process by explaining how the possibility of concurrency is treated in a structured manner.

\section{Proposals for policy development and communication \\ 4.1 Train all stakeholders}

This review of S12L applications has shown that M\&V entities and SANEDI specifically investigates whether concurrent benefits are claimed or not. This is, however, part of the M\&V process, which is highly technical [7]. Clear communication is, therefore, a challenge. It is recommended that basic $M \& V$ short courses (based on the S12L regulations [3] and SANS 50010 [8]) are provided to all role-players.

\subsection{Regulation 7 made more specific}

In its current form, Regulation 7 in terms of S12L [3] paints a very broad brush over the possible concurrencies which can exist. The exception is Regulation $7(\mathrm{c})$, which very specifically refers to a PPA under the IPP-bid programme as a concurrent benefit. More specific exclusions will increase certainty of taxpayers and role players. It is proposed that, upon review, Regulation 7 should be improved to specifically list all exclusions. The developed concurrency tests can also be extended to similar requirements in the regulatory structure. Notably, they can also be used to exclude limitations of allowance relating to renewable or conventional electricity generation, which cannot be claimed under S12L [3]. The same M\&V principles found applicable to concurrent benefits will also apply for the limitations of allowance.

\subsection{Establishment of a role-player association to promote engagements}

The case studies have shown that clear communication is critical where multiple stakeholders are involved. This is especially relevant to $\mathrm{S} 12 \mathrm{~L}$, which combines the technical field of energy efficiency projects with the financial field of tax incentives. It is recommended that an association is established between the legally appointed stakeholders (SANEDI and SANAS-accredited M\&V bodies) and other stake-holders (auditors, legal experts, tax ex- perts, taxpayers, consultants, etc.). It will also be appropriate to include Carbon Tax [30] under the same association. Similar to S12L, a carbon tax also reliant on an underlying technical process to quantify greenhouse gas emissions. Carbon tax combines this technical process with a new tax instrument under the Customs and Excises Act. Combining different disciplines in this field would make the association valuable in identifying uncertainties pro-actively.

\section{Conclusion}

S12L is intended to incentivise new energy efficiency savings. However, this study shows that there are multiple energy-related incentive programmes in South Africa. SANEDI and SANAS-accredited $M \& V$ entities are therefore legally appointed to investigate and ensure that S12L claims are accurate and compliant. Part of this process is to ensure that the incentive is not a concurrent benefit to other existing incentive programmes.

All role-players need to be satisfied that no concurrency exists, as that would bring S12L claims into question. Concurrency tests are therefore required. Although the M\&V process is highly technical, the basic concepts can be reduced to simple logic. This study therefore highlights the role of clear, non-technical communication as a key aspect of the S12L incentive.

This study shows that concurrency tests are conducted by SANEDI and M\&V entities. However, the stakeholders require additional assurance that no concurrent benefits are claimed. Simplified concurrency tests therefore provide an efficient manner to communicate these results without resorting to technical information.

Based on this study, proposals for policy development and improved communication are also made. These findings are also relevant to the carbon tax that was signed into law in South Africa in 2019.

\section{Author roles}

W. Hamer undertook the research for this project under Professor Mathews' supervision and prepared the article for submission. E.H. Mathews provided the initial problem statement, supervised the work and reviewed the draft manuscript. A.G.S Gous and J. Booysen provided technical information for the case studies and review the draft manuscript. J.C. Vosloo provided oversight of the study and review of the draft manuscript.

\section{References}

[1] Ateba, B. B. and Prinsloo, J. J. 2019. Strategic management for electricity supply sustainability in South Africa. Utilities Policy 56: 92-103.

[2] Parliament of the Republic of South Africa. 2012. Amendment of section 12L of Income Tax Act 58 of 1962. Taxation Laws Amendment Act of 2012.

[3] South African National Treasury. 2013. Regulations in terms of section 12L of the Income Tax Act, 1962, on the allowance for energy efficiency savings. Regulation Gazette No. 37136, 09 December 2013, Vol. 582, No. 10080. 
[4] Department of Energy. 2016. Post-2015 National Energy Efficiency Strategy. Online at http://www.energy.gov.za/files/policies/Draft-Post-2015-2030-National-Energy-Efficienciency-Strategy.pdf. Date of access: 09 Nov. 2020.

[5] Hamer, W., Booysen, W., and Mathews, E. H. 2017. A practical approach to managing uncertainty in the measurement and verification of energy efficiency savings. South African Journal of Industrial Engineering 28 (3): 128146.

[6] Presidency of the Republic of South Africa. 2016. Act No. 25 of 2015: Taxation Laws Amendment, 2015. National Gazette No. 39588, 08 January 2016, Vol. 607.

[7] South African Revenue Service. 2019. Interpretation Note 95 (Edition 2).

[8] South African National Standards. 2018. South African National Standard Measurement and verification of energy and demand savings. Pretoria: SABS Standards Division. (SANS 50010: 2018).

[9] Standing Committee on Finance: Report-back hearings. 2009. Taxation Laws Amendments Bills, 2009 Final Response Document.

[10] Department of Energy. 2010. Department of Energy South Africa Policy to support the Energy Efficiency and Demand Side Management Program for the Electricity Sector through the Standard Offer Incentive Scheme. Online at http://www.energy.gov.za/?les/policies/Standard0?erPolicy.pdf. Date of access: 07 Jul. 2020.

[11] South African Revenue Service. 2016. Interpretation Note 95 (Draft).

[12] South African Revenue Service. 2017. Interpretation Note 95 (Edition 1).

[13] U.S. Environmental Protection Agency. 2019. Guidebook for Energy Efficiency Evaluation, Measurement, and Verification. Online at https://www.epa.gov/sites/production/files/2019-06/documents/guidebook_for_energy_efficiency_evaluation_measurement_verification.pdf. Date of access: 09 Nov. 2020.

[14] Budge, M., Booysen, W., and Vosloo, J. C. 2015. Simplifying the process of identifying viable industrial energy efficiency incentives. 13 $3^{\text {th }}$ Conference on the Industrial and Commercial Use of Energy (ICUE), Cape Town, South Africa, 18-19 August, 2015: 212-219.

[15] Fortuin, W. 2013. Eskom's Integrated Demand Management (IDM) Programme and Funding Options. Online at http://www.ameu.co.za/Portals/16/Documents/EEDSMandRenewableEnergy/EskomIDMfundingoptions20111213.pdf. Date of access: 07 Jul. 2020.

[16] Eskom Holdings Limited. 2015. Eskom 2015 integrated report. Online at: http://www.eskom.co.za/IR2015/Documents/EskomIR2015single.pdf. Date of access: 07 Jul. 2020.

[17] Eskom Holdings Limited. 2015. MYPD3 Re-opener for selective items (2015/16-2017/18).

[18] South African Department of Energy. 2016. South African CDM Projects Portfolio. Online at: http://www.energy.gov.za/files/esources/kyoto/2016/South-African-CDM-Projects-Portfolio-up-to-19January2016.pdf. Date of access: 07 Jul. 2020.

[19] South African National Treasury. 2019. Draft explanatory memorandum on the draft Income Tax Amendment Bill, 2019.

[20] Department of Trade and Industry. 2014. 12I Approved projects since inception up to 30 April 2014.

[21] Department of Trade and Industry. 2015. Progress report on implementation of the Industrial Policy Action Plan (IPAP) for the financial year April 2014 to March 2015 to the Trade and Industry Portfolio Committee of the National Assembly.

[22] South African National Energy Development Institute. 2016. Section 12L of the Income Tax Act National Road Show, Midrand, South Africa, 2016.

[23] Department of Energy, National Treasury, and Development Bank of Southern Africa. 2019. Independent Power Producers Procurement Programme (IPPPP) An overview. Online at: https://www.ipp-projects.co.za/Publications. Date of access: 07 Jul. 2020.

[24] Eskom Holdings Limited. 2015. MYPD 3 Regulatory Clearing Account Submission to NERSA.

[25] Bright Hub Engineering. 2010. The Efficiency of Power Plants of Different Types. Online at: https://www.brighthubengineering.com/power-plants/72369-compare-the-efficiency-of-different-powerplants/. Date of access: 09 Nov. 2020.

[26] Johnson, K. A., Hamer, W., and Vosloo, J. C. 2019. Structuring uncertainty management for energy savings calculations. South African Journal of Industrial Engineering 30(3): 149-162.

[27] Janse Van Rensburg, H. M., Maneschijn, R., and Booysen, W. 2015. Selecting measurement boundaries for Section 12L energy efficiency tax applications: A mining case study. $13^{\text {th }}$ Conference on the Industrial and Commercial Use of Energy (ICUE), Cape Town, South Africa, 18-19 August, 2015: 263-271.

[28] Hamer, W., Booysen, W., and Mathews, E. 2018. A data quality evaluation framework for industrial energy efficiency reporting. 29th South African Institute of Industrial Engineering Annual Conference, Stellenbosch, South Africa, 24-26 October, 2018: 303-318.

[29] Campbell, K., Booysen, W., and Vosloo, J. C. 2017. Evaluating the feasibility of the 12L tax incentive for energyintensive industries. South African Journal of Industrial Engineering 28(3): 15-28.

[30] Presidency of the Republic of South Africa. 2019. Carbon Tax Act, 2019 (Act 15 of 2019). National Gazette No. 42483, 23 May 2019, Vol. 647. 